\title{
EXPERIMENTAÇÃO EM ASTRONOMIA: UMA PERSPECTIVA DA TEORIA DE APRENDIZAGEM SIGNIFICATIVA DE DAVID AUSUBEL EM UMA LICENCIATURA EM FÍSICA
}

\author{
Experimentation in astronomy: a perspective of David Ausubel's \\ significant learning theory in a physics degree
}

\section{Lucas Alves da Silva Prudente ${ }^{1 ;}$ Luis Henrique Precoma ${ }^{2}$; Angel Fidel Vilche Peña ${ }^{3}$}

\author{
${ }^{1}$ Unesp - Universidade Estadual Paulista \\ Pós - Graduando pelo Mestrado Nacional Profissional em Ensino de Física \\ Rua Wilson Calza; 120 - Presidente Prudente - SP \\ lucasprudenteas@hotmail.com \\ ${ }^{2}$ Unesp - Universidade Estadual Paulista \\ Departamento de Física \\ Rua João Gonçalves Foz, 1800 - Presidente Prudente - SP; CEP:19060-050 \\ I.precoma2@gmail.com \\ ${ }^{3}$ Unesp - Universidade Estadual Paulista \\ Departamento de Física \\ Rua Roberto Simonsen, 305 - Presidente Prudente - SP; CEP: 19060-900 \\ angel@fct.unesp.br
}

RESUMO - No cenário atual do ensino de astronomia, este que está dentre os temas abordados no ensino básico, tem se mostrado aquém de sua relevância, importância e significado em sua apresentação, evidenciando os cursos de formação de professores das áreas correlacionadas ao tema. Mediante este contexto, este trabalho elucidou a elaboração, construção e aplicação de dois equipamentos que apresentem de forma experimental a relação orbital entre o Sol e a Terra e seus fenômenos. O primeiro equipamento o simulador SolTerra, cujo ilustra de forma externa os fenômenos pertinentes à correlação entre os dois astros, e o segundo, uma maquete do movimento relativo solar onde relaciona os fenômenos existentes ao cotidiano do estudante. Como complemento e não menos importante, o presente trabalho apresenta a aplicação do kit aos estudantes de uma licenciatura com a utilização de roteiros de aplicação juntamente com questionários para verificação do nível de conhecimentos dos alunos graduandos antes e após a aplicação do mesmo, objetivando averiguar a eficácia do equipamento, possíveis melhorias e modificações.

Palavras-chave: ensino de astronomia; formação de professores; experimentação.

Recebido em: 05/06/2018

Revisado em: 27/08/2018

Aprovado em: 30/08/2018
ABSTRACT - In the present scenario of astronomy teaching, this one that is among the topics addressed in basic education, has been shown below its relevance, importance and meaning in its presentation, evidencing the teacher training courses in the areas related to the theme. Through this context, this paper elucidated the elaboration, construction and application of two equipments that experimentally present the orbital relation between the Sun 
and the Earth and its phenomena. The first equipment is the Sun-Earth simulator, which externally illustrates the phenomena pertinent to the correlation between the two stars, and the second, a model of the relative solar movement where it relates the phenomena that exist to the student's daily life. As a complement and not less important, the present study presents the application of the kit to undergraduate students with the use of application scripts along with questionnaires to verify the level of knowledge of undergraduate students before and after the application of the same, with the purpose of ascertaining the effectiveness of the equipment, possible improvements and modifications.

Keywords: teaching physics; teacher training; experimental teaching of astronomy; astronomy in high school. 


\section{INTRODUÇÃO}

Embora os Parâmetros Curriculares Nacionais (PCN+), elaborado pelo Governo Federal diga que o conteúdo de astronomia deve ser trabalhado no Ensino Médio na disciplina de Física, destaca-se a importância de o aluno reconhecer os fenômenos que estão presentes em seu cotidiano. Verifica-se que atualmente o Ensino de Astronomia é prejudicado e defasado por inúmeros fatores, como: material didático com erros conceituais, má formação de professores, dentre outras deficiências. Com esse quadro de ineficiência existente no Brasil, o conteúdo de astronomia à ser aplicado acaba sendo reduzido ou até extinto por instituições de ensino básico, conforme descrito por Langhi e Nardi 2009.

Observado este cenário, o referido trabalho volta-se a questão da formação inicial de professores de Física pela Universidade Estadual Paulista (Unesp) em seu curso de Licenciatura em Física, situada na cidade de Presidente Prudente - SP. Cujo no ano de 2015 a disciplina de Astronomia Básica foi introduzida na grade do curso como uma disciplina obrigatória com objetivos de:

Orientar os conteúdos de Física Básica no estudo da Astronomia e Conhecer $e$ manipular experiências demonstrativas. (PROGRAMA DE ENSINO DE GRADUAÇÃO)

Visto o panorama deste ramo da ciência na Educação Básica (Ensino Fundamental e Médio) e o caráter da disciplina no Ensino Superior. Este trabalho elucida a elaboração de um kit experimental sobre a relação orbital entre o Sol e a Terra e seus fenômenos criados.

Para a elaboração do material se torna necessário constatar alguns aspectos como, os fenômenos que eles vão representar, os elementos utilizados para construção e por fim o método de abordagem na aplicação.

Logo, para a análise dos conteúdos e fenômenos que os futuros professores devem estudar através do kit atenta-se em analisar o currículo descrito pelo Parâmetro Curriculares Nacional (PCN+) desenvolvido pelo Governo Federal para trazer subsídios voltados a Educação Básica, onde sua função é trazer uma nova visão da Física. Relações que antes não eram abordadas começaram a ser trabalhadas, entre elas analogias entre a vida do aluno através seu cotidiano e a Física; criando uma relação sólida entre elas, a interdisciplinaridade entre as disciplinas mesmo não sendo consideradas afins (porém com pontos em comum) e pôr fim a contextualização histórica mostrando a construção do conhecimento por meio das eras e os seus grandes nomes (BRASIL, 2002).

Desta forma foram elaborados seis temas estruturadores com o objetivo de organizar o Ensino de Física, como mostra o quadro 1:

Quadro 1. Relação de temas estruturadores Ensino Médio.

\begin{tabular}{|c|c|}
\hline F1 & Movimentos: variações e conservações \\
\hline F2 & $\begin{array}{c}\text { Calor, Ambiente, Fontes e Usos de } \\
\text { Energia }\end{array}$ \\
\hline F3 & $\begin{array}{c}\text { Equipamentos Eletromagnéticos e } \\
\text { Telecomunicações }\end{array}$ \\
\hline F4 & Som, Imagem e Informação \\
\hline F5 & Matéria e Radiação \\
\hline F6 & Universo, Terra e Vida \\
\hline
\end{tabular}

Fonte: (Brasil, 2002)

Considerando os 6 temas descritos pelo $\mathrm{PCN}+$ a serem trabalhados, o ensino de astronomia é incluído no tema F6: Universo, Terra e Vida; o qual é subdividido em três tópicos descritos pelo PCN+ Ensino Médio: O PCN+ no ensino de astronomia se divide em três temas:

i) Terra e sistema solar

ii) O Universo e sua origem

iii) Compreensão humana do Universo

De acordo com o currículo, os três temas devem ser trabalhos no primeiro ano 
do EM; sendo assim, o material desenvolvido por este trabalho se enquadra no primeiro tema. "Terra e Sistema solar".

Como já relatado, os desígnios do material desenvolvido encaixam-se de acordo com os descritos tanto na Educação Básica quanto no Ensino Superior dando subsídios para sua aplicação.

Em primeiro momento o trabalho busca a criação de um kit experimental em astronomia para que assim possa aplica-lo em um curso de licenciatura a modo de criar uma aprendizagem significativa descrita por David Ausubel em sua teoria e para embasamento de tais resultados utiliza-se de questionários iniciais e finais além da utilização roteiros experimentais para coletas de pontos cruciais à aplicação.

\section{DESENVOLVIMENTO}

De acordo com Reginaldo et al. (2012) as atividades experimentais têm a capacidade de despertar o interesse do educando pelo conteúdo apresentado. Sendo uma ferramenta de conexão dentre o embasamento teórico e o cotidiano dos envolvidos.

Porém ao analisar o cenário educacional o professor deve ter a capacidade de aplicação de materiais práticos em sua disciplina o que não ocorre normalmente, descrito por muitos as adversidades provindas do sistema educacional e financeiras desestimulam e impedem a utilização desta pratica em sua aula. Justificativa que por mais que tenha uma parcela de culpa, não explica a utilização de meios alternativos para tal acontecimento em sala de aula (SILVA, 2016).

$O$ ato da experimentação é de cunho importante para a formação do graduando, pois aquilo que ele vivencia em suas aulas práticas é posto em confronto com suas concepções iniciais, e a partir deste ponto cria-se um ponto de aprendizagem. Além de questões de percepção a realidade, atendimento as normas, erros/acertos apresentados na execução dos roteiros.
Levando ao ponto de o estudante descontruir hipóteses errôneas para reconstrução de outras, cujo representam de maneira correta o mundo que o cerca.

Dentre as práticas e teorias de ensino e aprendizagem, a que apresenta um subsidio ideal para execução do trabalho foi a elaborada e descrita pelo pesquisador e psicólogo David Ausubel (1918-2008) denominada Teoria de Aprendizagem Significativa (TAS). Pois se fundamenta no conhecimento inicial do aluno e utiliza-se dele como base para protagonizar a aprendizagem. Ausubel denota que professores devem criar situações didáticas que se relacionem a uma determinada estrutura cognitiva prévia com os novos conceitos (MORAES, 2005).

Para que ocorra a aprendizagem torna-se necessário duas condições, sendo que a primeira enfatiza o material abordado (livros, aulas, aplicativos, experimentos, etc.) como potencialmente significativo e a segunda o estudante tenha em sua estrutura cognitiva ideias-âncora relevantes com as quais esse material possa ser relacionado (experiências vividas, conceitos já aprendidos, etc.). Ao transpor esse cenário observa-se que os equipamentos respeitam tais preceitos descrito a cima, onde o kit além de apresentar o ponto de vista do cotidiano, cria-se a potencialidade em sua aplicação.

\section{CRIAÇÃO E APLICAÇÃO DO MATERIAL EXPERIMENTAL}

Para a execução do projeto é necessário levar em conta alguns fatores, sendo eles: Material necessário para construção, o projeto dos equipamentos, aplicabilidade e por fim os pontos de eficácias e de problemas apresentados em sua aplicação.

\subsection{Elaboração do material}

A criação do material observou alguns pontos, como material utilizado, disposição 
dos equipamentos para os fenômenos, mobilidade e por fim o custo de construção. Chegando ao projeto final usando placas e discos de MDF, lâmpada, cano PVC de construção, por fim papeis coloridos e cola, chegando ao resultado conforme a figura 1 .

Figura 1. kit experiental

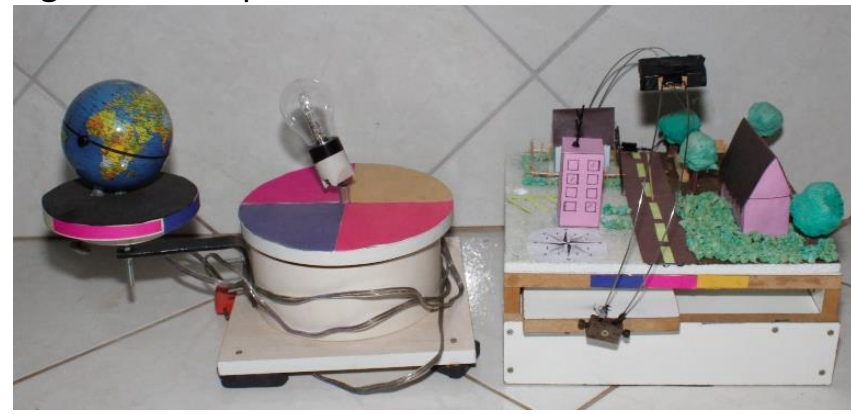

Fonte: Acervo do autor

O equipamento da esquerda é o simulador orbital Sol-Terra, emulando os conceitos de estações do ano, Solstícios e Equinócios, incidência solar em lugares próximos aos Polos. Já o da direita, trabalha questões sobre, posição relativa solar, pontos cardeais de aurora e crepúsculo solar, Sol a pino (zênite) e as sombras criadas em diferentes épocas do ano. Para ambos foi utilizado o mesmo padrão de cores (Amarelo, Rosa e Azul representando as estações), além da criação de um material roteirizado para otimizar a aplicação e direcionar os fenômenos de maior importância ao cotidiano deles.

\subsection{Aplicação do Material no Ensino Superior}

Como já mencionado, a escolha da turma foi do terceiro ano de Licenciatura em Física no ano de 2017, pois foi uma turma que não teve contato com a disciplina de astronomia básica até o referido momento. $\mathrm{A}$ aplicação foi dividida em três momentos: Pré-aplicação, com a utilização do questionário inicial; Aplicação do equipamento aos alunos e ao fim a utilização do questionário final.

O momento inicial foi selecionado a primeira aula da disciplina de astronomia básica, onde foi descrito o funcionamento das atividades para os alunos, onde onze aceitaram participar. Buscando otimizar o processo foi aplicado o questionário inicial a todos os alunos simultaneamente. Ao finalizarem o questionário os estudantes foram divididos em grupos de três a quatro integrantes e levados a outro local para execução do roteiro experimental, conforme a figura 2 .

Figura 2: Aplicação do Kit experimental.

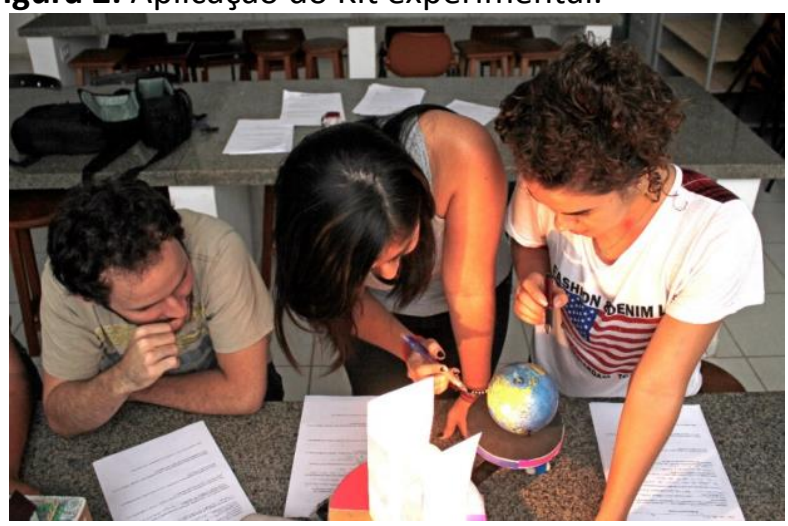

Fonte: Acervo do autor.

Ao termino desta etapa foi desenvolvido o questionário final afim de aferir pontos relevantes a aplicação do material.

\section{RESULTADOS}

De maneira sucinta os resultados com relevância ao trabalho serão apresentados nesta seção.

Ao questionário inicial o que se mostrou evidente foi o desconhecimento ou concepções errôneas sobre os fenômenos astronômicos criados pela relação Sol-Terra, em especial as estações do ano, sol a pino e pontos cardeais do aurora e crepúsculo solar.

A aplicação do material, logo de início foi verificada uma adesão positiva dos envolvidos com os equipamentos, o fato de manusearem de forma livre o Kit já mostra que outros fenômenos ou interpretações podem ser observados. Já na execução do roteiro experimental, ficou constatado a praticidade que 0 kit representa dos fenômenos.

Por fim, o questionário final buscou verificar em uma autoavaliação desde o nível de aprendizagem dos equipamentos até 
pontos onde os alunos apresentaram dificuldades, não concordam com o tema proposto além do material utilizado. A princípio buscou verificar a aprendizagem dos alunos através de uma autoavaliação onde obteve o gráfico 1.

Gráfico 1. Aprendizagem dos estudantes

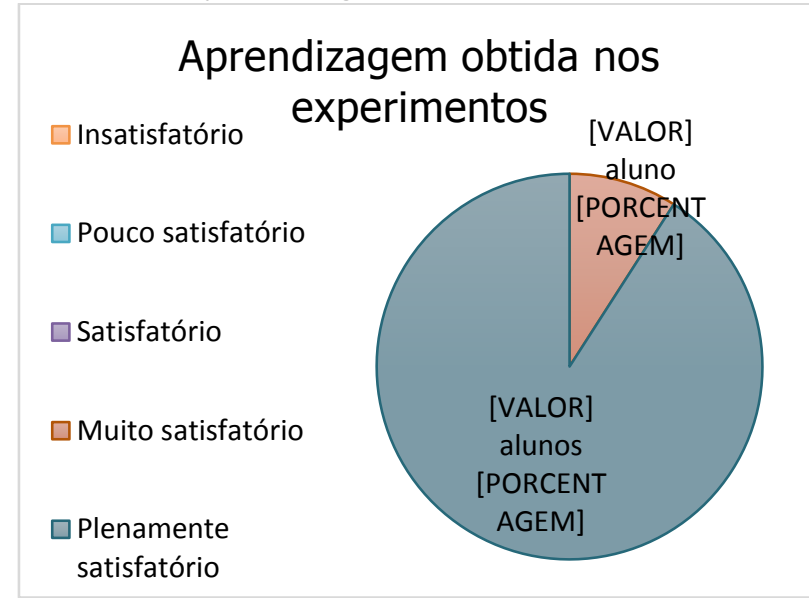

Fonte: Dados da pesquisa.

Dos 11 alunos envolvidos, todos apresentaram conceitos positivos sobre sua aprendizagem. Entretanto quando o foco é a qualidade dos equipamentos obteve-se 0 gráfico 2.

Gráfico 2: Qualidade do material experimental.

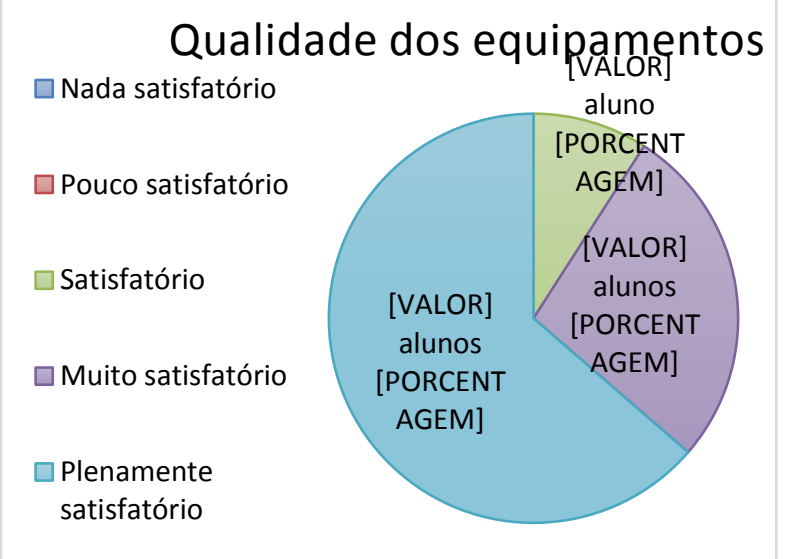

Fonte: Dados da pesquisa.

Tal ponto resultado evidencia a aprovação dos alunos mediante ao equipamento e sua qualidade de construção e aplicação onde todos os envolvidos sinalizaram o conceito de satisfatório ou mais.
Contudo a necessidade de também avaliar o roteiro de experimentação mostrase relevante tal como ilustra o gráfico 3 .

Gráfico 2: Qualidade do roteiro experimental

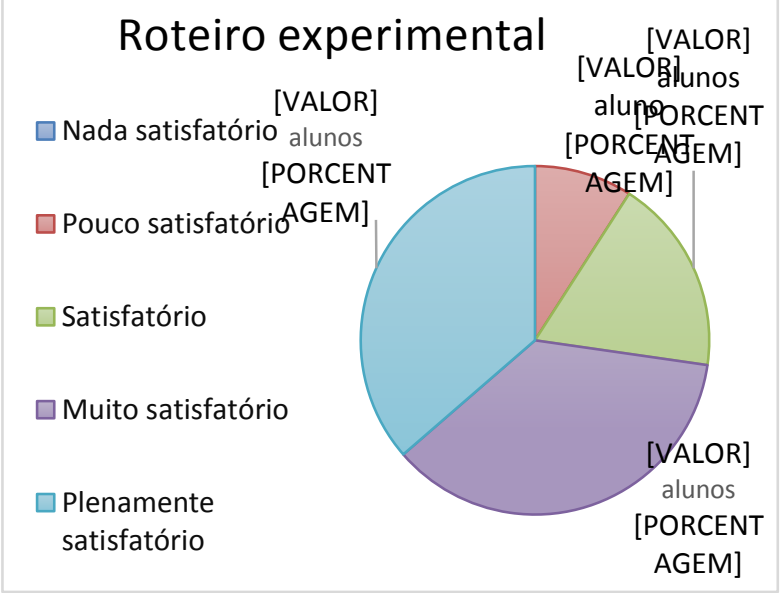

Fonte: Dados da pesquisa

Neste quesito evidenciou-se certa heterogeneidade das respostas dos alunos, mostrando do espectro de pouco satisfatório (9\%); satisfatório (18\%); muito satisfatório e plenamente satisfatório (@36\%).

\section{DISCUSSÕES}

A aplicação do material se mostrou viável, principalmente aos objetivos iniciais traçados pelo trabalho. Corroborados pelos resultados obtidos pelos questionários aplicados.

Mostrando que inicialmente boa parte dos entrevistados apresentaram deficiências conceituais sobre o tema de astronomia, cujo sobre a aplicação do kit foi possível verificar tal ocorrência. Refletindo a dificuldade apresentada por alguns na visualização das estações intermediarias (outono e primavera) e também referente ao conceito de Sol a pino.

Já quando abordado sobre os equipamentos, a maioria deles consideram satisfatório tanto a aplicação quanto o material experimental e o roteiro. Porém a roteirização necessita de certa adequação, pois houve avaliações abaixo do esperado. 


\section{CONSIDERAÇÕES FINAIS}

A experimentação por si só acarreta uma visão paralela dos fenômenos experimentado pelos alunos aos conceitos apresentados, podendo corroborar ou desmistificar conceitos prévios. Embora a experimentação não é abordada de maneira ideal na Educação Básica, demonstrando desconhecimento por parte dos professores que por sua vez foram alunos em sua graduação. A experimentação quando trabalhado de maneira ideal com um material potencialmente significativo ao aluno correlacionado com seu cotidiano a sua abordagem dos fenômenos demonstrou-se rica para os envolvidos criando uma ponte entre 0 novo conhecimento com 0 conhecimento já adquirido em seu cotidiano.

\section{REFERÊNCIAS}

BRASIL. Ministério da Educação. PCN+ Ensino Médio: Orientações Educacionais Complementares aos Parâmetros Curriculares Nacionais - Ciências da Natureza, Matemática e suas Tecnologias. Brasília: MEC/SEMTEC, 2002.

LANGHI, R.; NARDI, R. Ensino da astronomia no Brasil: educação formal, informal, não formal e divulgação científica. Revista Brasileira de Ensino de Física, v. 31, n. 4, 2009.

MORAES, R.M. A teoria da aprendizagem significativa - tas. 2005. Disponível em: http://www.construirnoticias.com.br/ateoria-da-aprendizagem-significativa-tas/ Acesso em: 02 de março de 2017.

SILVA, V.G. A importância da experimentação no ensino de química. 2016. Trabalho (Conclusão de Curso) - Universidade Estadual Paulista, Bauru, 2016.

REGINALDO, C.C. et al. O ensino de ciências e a experimentação. In: ANPED SUL, 9. Anais... Rio Grande do Sul, 2012. 